удК 343

А. В. Путинцев

Казанский (Приволжский) федеральный университет, 2. Казань, Российская Федерация

\title{
ПРОБЛЕМА ОБЪЕКТА ОТНОШЕНИЯ УГОЛОВНО-ПРАВОВОЙ ОТВЕТСТВЕННОСТИ \\ В РУССКОЙ ЮРИДИЧЕСКОЙ МЫСЛИ ВТОРОЙ ПОЛОВИНЫ ХІХ - НАЧАЛА ХХ ВЕКА
}

\begin{abstract}
АНнотАЦИЯ. Данная статья основана на ретроспективном обзоре уголовно-правовой литературы дореволюционного периода, посвященной проблеме «объекта наказания» . Делается попытка связать взгляды ученых второй половины XIX — начала XX века с современной концепцией объекта правоотношения уголовно-правовой ответственности путем установления общих смыслов в используемой терминологии. Предлагается выделение классического, социологического и компромиссного направления в изучении проблематики объекта наказания в зависимости от явлений, признаваемых учеными в качестве объекта наказания, дается периодизация каждого направления. Автор указывает на уровень востребованности законодателем и степень влияния этих подходов на современную картину взглядов на объект правоотношения уголовной ответственности. На базе изученного материала отмечается корреляция между объектом правоотношения уголовной ответственности, юридическими фактами, лежащими в основе этой ответственности и целями наказания, что характеризует место правоотношения уголовной ответственности в механизме правового регулирования. КЛЮЧЕВЫЕ СЛОВА. История правовой мысли; правоотношение уголовной ответственности; объект уголовно-правового отношения; объект наказания; объект уголовной ответственности; основания уголовной ответственности.

ИНФОРМАЦИЯ О СТАТЬЕ. Дата поступления 23 июля 2017 г.; дата принятия к печати 11 октября 2017 г.; дата онлайн-размещения 25 октября 2017 г.
\end{abstract}

A. V. Putintsev

Kazan Federal University,

Kazan, Russian Federation

\section{OBJECT OF RELATIONS OF CRIMINAL AND LEGAL LIABILITY AS A PROBLEM IN RUSSIAN LEGAL THOUGHT IN MID $19^{\mathrm{TH}}-$ EARLY 20 ${ }^{\mathrm{TH}}$ CENTURY}

ABSTRACT. This article is based on a retrospective review of the Russian criminal and legal literature of the pre-revolutionary period devoted to the problem of the «object of punishment». An attempt is made to link the views of scientists of the second half of the 19th century and the beginning of the 20th century with the modern concept of the object of legal relationship of criminal and legal liability by establishing common meanings in the terminology used. The article offers to identify classical, sociological and compromise approaches to studying the problematics of the object of punishment depending on the phenomena recognized by scientists as an object of punishment and gives the periodization of each approach. The author points to the relevance level by the lawmaker and the degree of influence of these approaches on the modern picture of views on the object of legal criminal liability relations. On the basis of the material studied, the article notes the correlation between the object of legal criminal liability relations, the legal facts underlying this liability and the purposes of punishment, which characterizes the place of the legal criminal liability in the mechanism of legal regulation.

KEYWORDS. History of legal thought; legal relationship of criminal liability; object of criminal and legal relationship; object of punishment; object of criminal liability; grounds for criminal liability.

ARTICLE INFO. Received July 23, 2017; accepted October 11, 2017; available online October 25, 2017.

(C) А. В. Путинцев, 2017

\section{Baikal Research Journal}

электронный научный журнал Байкальского государственного университета 
В современной юридической науке распространен подход к юридической ответственности как к правоотношению [1, с. 73], однако следует отметить, что теория правоотношения все еще продолжает оставаться площадкой для дискуссий. Так, вопрос о структуре правоотношения в целом решен в смысле выделения в нем субъектов и содержания (под которым чаще всего понимаются субъективные права и юридические обязанности сторон правоотношения либо поведение его участников). Объект обычно также включается в структуру правоотношения, однако единства в понимании того, что же является объектом правоотношения, в литературе не наблюдается. Широкое распространение получили описательные дефиниции: «то, на что направлено правоотношение» или «то, по поводу чего складывается правоотношение». Общетеоретический и уголовно-правовой обзоры проблемы объекта правоотношения ответственности, проведенные И. А. Кузьминым [2] и Н. В. Генрих [3] соответственно, позволяют констатировать существование довольно большого спектра взглядов на интересующую нас проблему.

В рамках настоящей статьи мы постараемся проследить эволюцию взглядов на объект правоотношения уголовной ответственности в отечественной юридической мысли второй половины XIX - начала XX века. В этот период наука уголовного права переживала стадию своего становления, а работы ученых уголовно-правового цикла содержали рефлексию, интересную и с общетеоретических позиций. Ее изучение позволит понять динамику формирования современных подходов к объекту правоотношения уголовной ответственности.

Поставленная задача требует нескольких предварительных методологических замечаний. Во-первых, в теории права по-прежнему слабо разграничены категории уголовного правоотношения, регулятивного и охранительного уголовного правоотношения, правоотношения уголовной ответственности $[4$, с. $20 ; 5$, с. 143]. Не вдаваясь в эту дискуссию, считаем возможным в самом общем виде определить правоотношение уголовной ответственности как вид конкретных охранительных уголовно-правовых отношений, возникающих по поводу фактов, с которыми законодатель в процессе осуществления уголовной политики связывает наступление уголовной ответственности. Предлагаемый подход учитывает роль правоотношения уголовной ответственности как правового средства в рамках механизма правового регулирования.

Во-вторых, несмотря на неизбежные анахронизмы терминологии, думается, что полемика об «объекте наказания» в дореволюционной уголовно-правовой мысли может быть интерпретирована как дискуссия об объекте отношения, в рамках которого реализуется уголовная ответственность. Объект наказания включает в себя весь спектр общественных явлений, внести изменения в которые призвано наказание, и отражает в единстве уголовно-политический (направленность механизма уголовно-правового регулирования) и уголовно-правоприменительный (направленность конкретного охранительного правоотношения) смыслы. В ходе дальнейшего изложения материала выражения «объект наказания» и «объект отношения уголовно-правовой ответственности» будут употребляться как синонимы.

B-третьих, неразрывно с вопросом об объекте наказания связан вопрос об основании применения наказания, который может быть интерпретирован как вопрос об основании уголовной ответственности, или шире, как вопрос о юридическом факте либо фактическом составе, с которым уголовная политика связывает применение уголовной ответственности. Если в теории государства и права, возникшей на базе развитого уголовного законодательства, вопрос об основании ответственности решается как сам собой разумеющийся [6, с. 56], то в период, рассматриваемый в статье, можно увидеть различные взгляды на эту проблему. Как будет показано ниже, при теоретическом осмыслении структуры уголовного правоот-

\section{Baikal Research Journal}

электронный научный журнал Байкальского государственного университета 
ношения можно будет выявить определенную корреляцию между объектом правоотношения уголовно-правовой ответственности и основанием ответственности. В ходе дальнейшего изложения выражения «основание применения наказания», «основание уголовной ответственности», «юридический факт, с которым уголовная политика связывает возникновение правоотношения уголовной ответственности» будут употребляться как синонимы.

Следует отметить, что до определенного времени вопрос об объекте наказания не выделялся в отдельную научную проблему. Вплоть до второй половины XIX века общепризнанным считалось, что единственным объектом наказания является преступление, а единственным основанием ответственности - вина. На наш взгляд, это обусловлено как влиянием на отечественных ученых немецкой классической школы, основанной на кантианском и гегелевском идеализме, так и тем, что уголовное право отошло от казуального понимания преступлений как отдельных общественно-опасных деяний и сформулировало подход к преступлению как к общественно-опасному нарушению нормы права, порывая с идеей рефлекторного возмездия и связанного с ней объективного вменения. В дальнейшем можно отметить три точки зрения на интересующую нас проблему: классическую, социолого-правовую и компромиссную.

Становление классического взгляда на объект наказания в отечественной правовой мысли происходило в три этапа.

Первый этап связан с влиянием учений немецких авторов на отечественную уголовно-правовую школу. На этом этапе происходит становление догмы юридической науки как таковой, создаются необходимые предпосылки для четкого оформления взглядов на вопрос об объекте наказания.

Второй этап связан с появлением в Италии антропологической школы, базирующейся на теории врожденного преступника, которая отвергала преступление как основание ответственности. С выходом в 1876 году сочинения основоположника школы Ч. Ломброзо «Человек преступный» разразилась обширная дискуссия, и выработанные консервативно настроенными учеными положения легли в основу классической позиции.

Третий этап (1880-е) связан с появлением социологической школы и теории личного состояния преступности. Полемика со сторонниками нового направления привела к уточнению взглядов классической школы на вопрос об объекте наказания.

В русской правовой мысли классические позиции заняли Н. С. Таганцев и Н. Д. Сергеевский, более радикально выступал последний. С его точки зрения, объектом карательной деятельности государства является нарушение нормы, а наказание - закономерной на него реакцией правопорядка. Что же касается преступника, то он «может быть нравствен или безнравствен, добр или зол, праведен и греховен - все это не имеет существенного значения» [7, с. 57]. Единственным существенным свойством преступника Н.Д. Сергеевский считает то, что он либо не согласен с законами общества, либо сознательно их нарушает. Таким образом, автор придает значение только преступлению и вине.

Н.С. Таганцев более гибок в своих построениях. Он пишет, что «объектом карательной деятельности государства является лицо, но при этом только лицо, учинившее запрещенное законом деяние, признанное виновным в нем и отвечающее не только по поводу этого деяния, но и за это деяние» $[8$, с. 81]. Однако ученый неоднократно подчеркивает приоритет преступления, что в процессе дискуссии с И. Я. Фойницким заставляет его значительно переформулировать это положение. Итак, «объектом карательной деятельности является преступное

\section{Baikal Research Journal}

электронный научный журнал Байкальского государственного университета 
деяние, как проявление личности, подлежащей за учиненное им известным стеснениям, наказанию» [8, с. 87].

Таким образом, несмотря на определенную градацию смысловых оттенков, в обоих случаях мы получаем четкое теоретическое построение, в котором объектом правоотношения юридической ответственности является преступление, решающим юридическим фактом, делающим возможным применение наказания - вина, а свойства преступника если и имеют какое-то значение, то лишь факультативное. Интерпретируя в современных категориях, можно сказать, что для классической точки зрения объектом правоотношение уголовной ответственности является преступление как то, по поводу чего складывается правоотношение.

Другую позицию составляет группа теорий, ставящая знак тождества между объектом и одним из субъектов правоотношения - преступником. При этом юридическим фактом, с которым с точки зрения уголовной политики должно связываться возникновение правоотношения уголовной ответственности, признавались самые разнообразные явления.

Хронологически научные поиски в данном направлении можно разделить на два этапа. Первый затрагивает период неразработанности вопроса и господства классических воззрений. Работы этого периода зачастую носят следы влияния учений отдельных немецких авторов - сторонников теории исправляющего наказания. Вопрос не всегда четко ставится. Хорошим примером таких поисков являются воззрения В. Д. Спасовича, который в своей работе упоминает, что государство должно уважать в субъекте преступления личность и «только и может репрессивно действовать на преступника и стесняя его... в благах" [9, с. 181]. Наказание же, по мысли В. Д. Спасовича, «обусловливается преступлением и оправдывается только крайнею необходимостью обезоружить преступника и притом только его одного" [9, с. 180]. В рамках данного подхода субъект и объект правоотношения тождественны друг другу, а основания ответственности заимствованы из классического подхода.

На втором этапе взгляд на личность как на единственный объект наказания получает четкое оформление. Становление этапа связано с деятельностью профессора И. Я. Фойницкого, впервые сформулировавшего свою теорию в начале 1870 -х годов, которая в окончательном виде прозвучала в «Учении о наказании в связи с тюрьмоведением» в 1889-м году. На этом этапе поиски ведутся главным образом усилиями сторонников социологического направления в науке уголовного права, которые видели основание применения наказания во внутреннем мире преступника, что привело к выработке понятия «личного состояние преступности».

В российской юридической науке его впервые ввел в оборот И. Я. Фойиицкий. В его трудах оно прошло значительную эволюцию от попыток связать преступность и ее выражения в единый предмет науки уголовного права [10, с. 398-413] до финального определения, воспринятого наукой. В заключительной формулировке личное состояние преступности понималось как располагаемая человеком сумма положительных и отрицательных душевных способностей (волевых и сознательных), заключающая в себе внутреннюю возможность преступной деятельности $[11$, с. 18]. Автор теории считал, что это состояние преступности и есть «предмет наказания» [12, с. 42]. Для усвоения авторской позиции важно понимать, что автор определял объект наказания как «личные условия преступления». Такими условиями являлись привычки и состояние волевой способности. Именно на них должны были быть направлены меры уголовной ответственности. Сам факт преступления играл лишь роль последнего юридического факта в сложном фактическом составе, делающим возможным возникновение правоотношения уголовной ответственности. Само преступление не должно быть наказуемо по-

\section{Baikal Research Journal}

электронный научный журнал Байкальского государственного университета 
стольку, поскольку обусловлено объективными причинами - космическими (г.е. природными) и общественными. Наказание может бороться лишь с субъективными причинами, сделавшими возможным совершение преступления данным лицом [12, с. 40-42], причем в той мере, в которой эти причины проявились.

Учение И. Я. Фойницкого получило развитие в работах В. В. Есипова. Во- первых, он уточнил, что объектом наказания «является, конечно, не преступное состояние, не преступность, как нечто отвлеченное, не преступное деяние, а отдельная человеческая личность преступника как субъекта преступления» [13, с. 317], устранив тем самым терминологическую неопределенность, свойственную определениям И. Я. Фойницкого. Во-вторых, В. В. Есипов установил связь между традиционными формами вины и личного состояния, положив в основу критерий степени напряжения волевой способности при проявлении деятельности вовне. Согласно его классификации, личное состояние преступности проявляется вовне в форме умышленной вины и характеризуется избыточным напряжением сознательных и волевых способностей по отношению к преступной цели. Личное состояние опасности, проявляющееся вовне в форме вины неосторожной, характеризуется, напротив, недостаточным напряжением волевых способностей [13, с. 188-189].

Д. А. Дриль исходит из сходства между психическими отклонениями и преступностью. Ученый считает, что в карательной деятельности, как и в медицине, необходимо определить субъективные причины преступности, а потом избрать наиболее целесообразные средства для их устранения [14, с. 471]. Призванное бороться с преступлением, наказание должно бороться с его причиной, ближайшей же причиной является именно определенное состояние человека. Таким образом, видя основание применения наказания в деянии, но лишь в смысле обнаружения симптомов болезни, Д. А. Дриль во многом солидаризируется с И. Я. Фойницким, лишь в большей степени акцентируясь на медицинской и физиологической стороне вопроса.

Завершая разговор о второй группе теорий, нельзя не упомянуть о С. К. Гогеле. Так же, как для ранних классиков не существовало вопроса об объекте наказания (таким объектом могло быть только преступление), так и для этого ученого вопрос не представлял проблемы. На его взгляд, объектом наказания, безусловно, являлась личность. Автор, рассматривая в тесной связи вопросы о цели и объекте наказания, уверенно проводит границу между старым и новым как раз по роли личности для законодателя. Замечая, что если нынче личность становится объектом наказания во всех смыслах, то единственной целью должно быть исправление, автор предсказывает наказанию как правовому институту скорое упразднение [15, с. $167-187]$.

Таким образом, объектом правоотношения уголовной ответственности здесь выступают либо сам преступник либо его определенные свойства. Юридические факты, делающие возможным применение наказания в данных теориях отличались большим разнообразием. В целом данная группа теорий исходит, выражаясь современным научным языком, из того, что объект правоотношения - это то, на что оно направлено, на что воздействует правоотношение.

Логическим продолжением дискуссии после формирования крайних позиций должно было стать появление компромиссных построений, исходящих из двойственности объекта наказания. Как совершенно справедливо заметил В. В. Есипов, каждая из школ неоправданно стремилась быть односторонней, что зачастую приводило к спору из-за слов, а не из-за понятий [13, с. 311].

Первую попытку компромисса, еще нечеткую, мы встречаем в научном творчестве А. Ф. Кистяковского. Наиболее четко черты его позиции проявились во втором издании его «Учебника». Среди прочего, в нем автор заметил, что нака-

\section{Baikal Research Journal}

электронный научный журнал Байкальского государственного университета 
зание «должно быть обеспечительно и влиятельно», понимая под первым свойством эффективное действие на преступника, а под вторым - на общество [16, c. 769]. По нашему мнению, из вышесказанного следует вывод о попытке указать на двойственность объекта правоотношения уголовной ответственности, которая направлена как на личность преступника, так и на общество.

Осознанные попытки компромисса мы встречаем на рубеже веков. М. П. Чубинский, рассматривая объект уголовной репрессии, выделяет в качестве объекта и преступление, как повод к осуществлению карательного воздействия, и личность преступника, как объект приложения репрессии. Заслуга М. П. Чубинского в выделении мотива в отдельный элемент объекта наказания [17, с. 388-402]. Самого преступления и преступника недостаточно для решения вопроса о мере наказания. Именно мотив выступает связующим звеном между деянием и деятелем, является индикатором психического отношения преступника к своему преступлению.

Таким образом, в качестве объекта правоотношения уголовной ответственности ученым выделялся комплекс из преступления и преступника, а третьим элементом и одновременно основанием применения наказания провозглашался мотив. Следовательно, М. П. Чубинский все же отдает приоритет личности и субъективным основаниям применения наказания. Вместе с тем, как видно из изложенного выше, данный ученый не вполне последователен в теоретических основаниях разграничения объекта наказания и оснований его применения.

С. П. Мокринский в своем рассуждении отталкивается от того, что объект правоотношения уголовной ответственности не может быть выбран абсолютно, и прямо зависит от цели, преследуемой законодателем при реализации конкретного наказания. В случае, когда целью является общая превенция, объектом ставится преступление, в случае формулирования цели как специальной превенции объектом является личность. Идеальной моделью ученому видится компромиссная система, преследующая обе цели. Поскольку такой компромисс достижим лишь на основе системы общей превенции, то преобладающим объектом наказания должно быть преступление, а факультативным - личность [18, с. 155-156]. Примат преступления отразился и на основаниях уголовной ответственности. По терминологии автора, предположением репрессии может служить либо действие, либо результат. Отталкиваясь от понятия опасности действия, автор смешивает объективный критерий опасности с субъективными критериями виновности, считая опасным действие не само по себе, а производимое с определенным отношением воли [19, с. 391]. В этом построении, на наш взгляд, прослеживаются характерные черты учения личного состояния преступности, поскольку действие рассматривается как выражение внутренних особенностей преступника.

Компромиссом, на наш взгляд, является и позиция С. В. Познышева. Объектом воздействия наказания, согласно ей, выступает личность: «наказание должно быть способно удержать человека от повторного совершения данного преступления» [20, с. 157]. Однако далее у него встречаем: «само собой разумеется, что наказание, способное сломить уже сложившуюся и заявившую себя волю преступника, будет достаточным для общего предупреждения преступлений»[20, с. 157]. Видно, что объект, на который должно быть направлено уголовное правоотношение, у данного автора носил смешанный характер, однако, в отличие от С. П. Мокринского, приоритет отдавался специальной, а не общей превенции. На взгляд С. В. Познышева это соотношение не требует доказательств, причины лежат в самой сущности наказания. Что же касается решающего основания применения наказания, то им является вина. С. В. Познышев не видит смысла в понятии «личное состояние преступности». Наказание должно определяться двумя мо-

\section{Baikal Research Journal}

электронный научный журнал Байкальского государственного университета 
ментами. Во-первых, характером вины, которая в необходимом объеме выражает свойства личности. Во-вторых, соотношением этой вины с внутренним миром человека. Узость и абстрактность понятия вины в законодательстве, отсутствие классификации преступников и привели к появлению теории личного состояния преступности [21, с. 267-269].

Аналогичным образом строится и теория Л. Е. Владимирова. Согласно его учению, объект наказания имеет двоичную структуру. В его состав входит, во-первых, преступник, а, во-вторых, та социальная группа, членом которой он является и в которой он сформировался как личность [22, с. 20]. Основанием применения наказания является недостаток чувства ответственности, проявившийся в нравственных пороках, которые, в свою очередь, проявляются в преступлении.

Таким образом, группа компромиссных теорий исходит из двойственного характера объекта правоотношения уголовной ответственности, выделяя в его качестве, в одной из модификаций, личность преступника и преступление либо как явление идеального порядка, либо в смысле, близком криминологической категории «уровень преступности». В модификации Л. Е. Владимирова вторым объектом воздействия наказания выступала социальная группа, ответственная за воспитание преступника. В любом случае, для этой группы мыслителей объект правоотношения - это то, на что оно направлено.

Из сказанного видно, что проблема занимала важное место в отечественной уголовно-правовой литературе, и за период с середины XIX века до революции ее решения прошли развитие от господства прогрессивной для своего времени, но перестававшей отвечать требованиям современности старой школы до непримиримой дискуссии, а от неё - к поиску компромисса. По сравнению с современными прочтениями теории объекта правоотношения уголовной ответственности правоведы прошлого связывали его с социально-правовыми категориями преступления, личности преступника, общества, а не с чисто юридическими категориями уголовной ответственности, наказания, правового статуса преступника, причиной чего следует видеть качественно иное состояние теории права и уголовно-правовой теории, теснее связанной с осмыслением философского смысла и социального значения уголовного права.

Вместе с тем классический подход, представленный работами Н. Д. Сергеевского и Н. С. Таганцева, не претерпел с тех пор существенных изменений до сих пор встречается в юридической литературе, реализуется в правоприменительной практике, поскольку достаточно удобен. Однако выделение объекта в самостоятельный элемент структуры правоотношения юридической ответственности в познавательном плане при таком подходе имеет небольшое значение.

Альтернативные точки зрения генетически были теснее связаны с вопросами уголовной политики. Поскольку правоотношение уголовной ответственности, явяляясь частью механизма уголовного правового регулирования, имеет определенные цели и призвано воздействовать на определенные социальные явления, постольку законодательное (прямое или опосредованное) формулирование объекта правоотношения определяет содержание этого правоотношения в виде прав и обязанностей его участников, что в уголовном праве выражается в характере уголовного процесса и в конкретных мерах наказания. Заслуживает внимания мысль о том, что целям наказания соответствуют свои специфические объекты правоотношения: цели социальной справедливости как объект соответствует преступление, специальной превенции - личность преступника, общей превенции - общество в целом и отдельные социальные группы.

$\mathrm{C}$ формулировкой объекта правоотношения уголовной ответственности при такой постановке вопроса коррелирует и вопрос о юридических фактах, лежащих

\section{Baikal Research Journal}

электронный научный журнал Байкальского государственного университета 
в основе такого правоотношения. Эта зависимость может быть выражена следующим образом. Если объектом правоотношения является преступление, неотъемлемым юридическим фактом, лежащим в основе юридической ответственности, будет вина, если объектом правоотношения является личность либо социальная группа, потребуется установление дополнительных юридических фактов, как, например, «опасное состояние личности», мотив или нравственные связей между преступником и его социальной средой. Ввиду сложности своей практической реализации на уровне правоприменения такие трактовки, как правило, систематически отвергаются законодателем, вместе с тем, на наш взгляд, их следует учитывать при конструировании механизма правового регулирования в рамках осуществления уголовно-правовой политики..

\section{Список использованной литературы}

1. Фильченко А. П. Уголовная ответственность как правоотношение: истоки и перспективы развития теоретической концепции / А. П. Фильченко // Человек: преступление и наказание. -2012 . - № $3 .-$ С. $72-75$.

2. Кузьмин И. А. Объект материального правоотношения юридической ответственности / И. А. Кузьмин // Вестник ВГУ. Серия «Право». - 2013. - № 1. - С. 92-100.

3. Генрих Н. В. Объект как элемент структуры уголовно-правового отношения / Н. В. Генрих // Ленинградский юридический журнал. - 2010. - № 3. - С. 14-25.

4. Маркунцов С. А. Некоторые размышления об объекте общезапретительных уголовно-правовых отношений / С. А. Маркунцов // Сибирский юридический вестник. - 2016. № 4. - C. 20-26.

5.Юшков А. В. К вопросу об охранительных отношениях / А. В. Юшков // Молодые ученые. - 2013. - № 4. - С. 142-144.

6. Гогин А. А. Правонарушение как юридический факт, обусловливающий правоотношение юридической ответственности / А. А. Гогин // Вектор науки ТГУ. - 2011. № 1. - С. 54-58.

7. Сергеевский Н. Д. Русское уголовное право. Часть общая. Пособие к лекциям / Н. Д. Сергеевский. - СПб. : Тип. М.М. Стасюлевича, 1913. - 395 с.

8. Таганцев Н. С. Русское уголовное право. Лекции : Часть общая. В 2-х т. / Н. С. Таганцев. - М. : Наука, 1994. - T. 2. - 393 с.

9. Спасович В. Д. Учебник уголовного права. В 2 т. / В. Д. Спасович. - СПб. : Тип. И. Огризко, 1863. - Т. 1. - 442 с.

10. Фойницкий И. Я. На досуге. Сборник юридических статей и исследований с 1870 г. Т. 2 / И. Я. Фойницкий. - СПб. : Тип. М.М. Стасюлевича, 1900. - 608 с.

11. Фойницкий И. Я. Уголовно-правовая доктрина о соучастии / И. Я. Фойницкий // Юридический вестник. - 1891. - Т. VII. Кн. 1, № 1. - С. 3-28.

12. Фойницкий И. Я. Учение о наказании в связи с тюрьмоведением / И. Я. Фойницкий. - М. : Городец, Добросвет-2000, 2000. - 464 с.

13. Есипов В. В. Очерк русского уголовного права: Преступление и преступники. Наказание и наказуемые. Часть общая / В. В. Есипов. - 2-е изд., пересмотр. - СПб. : Тип. Н. В. Васильева, 1898. - 402 с.

14. Дриль Д. А. Учение о преступности и о мерах борьбы с нею / Д. А. Дриль. - СПб. : Шиповник, 1912. - 702 с.

15. Гогель С. К. Курс уголовной политики в связи с уголовной социологией / С. К. Гогель. - СПб. : Юрид. кн. скл. «Право», 1910. - 516 с.

16. Кистяковский А. Ф. Элементарный учебник общего уголовного права с подробным изложением начал русского уголовного законодательства. Часть общая / А. Ф. Кистяковский. - 2-е испр. и значит. доп. изд. - Киев : Тип. И. и А. Давиденко, $1882 .-972$ с.

17. Чубинский М. П. Курс уголовной политики / М. П. Чубинский. - Ярославль : Тип. Губ. правл., 1909. - 450 с.

18. Мокринский С. П. Наказание, его цели и предположения : в 3 ч. Ч. 1. Общее и специальное предупреждение преступлений / С. П. Мокринский. - М. : Унив. Тип., 1902. - 157 c.

\section{Baikal Research Journal}


19. Мокринский С. П. Наказание, его цели и предположения : в 3 ч. Ч. 3. Казуальный и потенциальный моменты действия / С. П. Мокринский. - Томск : Паровая типолитогр. П. И. Макушина, 1905. - 263 с.

20. Познышев С. В. Учение о карательных мерах и мере наказания. Курс, составленный по лекциям / С. В. Познышев. - М. : О-во взаимопомощи студентов-юристов Моск. ун-та, 1908. - 185 с.

21. Познышев С. В. Основные начала науки уголовного права: Общая часть уголовного права / С. В. Познышев. - 2-е изд., испр. и доп. - М. : А. А. Карцев, 1912. - 668 с.

22. Владимиров Л. Е. Курс уголовного права : в 2 ч. Ч. 1. Основы нынешнего уголовного права / Л. Е. Владимиров. - М. : Т-во И. Д. Сытина, 1908. — 400 с.

\section{References}

1. Fil'chenko A. P. Criminal liability as a jural relation: sources and prospects of theoretical concept development. Chelovek: prestuplenie $i$ nakazanie = Man: Crime and Punishment, 2012, no 3, pp. 72-75. (In Russian).

2. Kuz'min I. A. Object of material jural relation of legal liability. Vestnik VGU. Seriya "Pravo»= Bulletin of VSU. Series «Law», 2013, no 1, pp. 92-100. (In Russian).

3. Genrikh N. V Object as structure element of criminal and legal relation. Leningradskii yuridicheskii zhurnal = Leningrad Juridical Journal, 2010, no 3, pp. 14-25. (In Russian).

4. Markuntsov S. A. Some reflections on object of general prohibitive criminal and legal relations. Sibirskii yuridicheskii vestnik = Siberian Juridical Bulletin, 2016, no 4, pp. 20-26. (In Russian).

5. Yushkov A. V. On issue of protective relationships. Molodye uchenye = Young Scientists, 2013, no 4, pp. 142-144. (In Russian).

6. Gogin A. A. Violation of law as a juridical fact determining legal relation of legal liability. Vektor nauki $T G U=$ Vector of Science of TSU, 2011, no 1, pp. 54-58. (In Russian).

7. Sergeevskii N. D. Russkoe ugolovnoe pravo. Chast' obshchaya [Russian Criminal Law. Part General]. Saint Petersburg, M.M. Stasyulevich Publ., 1913. 395 p.

8. Tagantsev N. S. Russkoe ugolovnoe pravo. Lektsii : Chast' obshchaya. V 2-kh t. [Russian Criminal Law. Lectures: General Part. In two volumes]. Moscow, Nauka Publ., 1994, vol. 2. $393 \mathrm{p}$.

9. Spasovich V. D. Uchebnik ugolovnogo prava. V 2-kh t. [Textbook of Criminal Law. In 2 parts]. Saint Petersburg, I. Ogrizko Publ., 1863. vol. 1, 442 p.

10. Foinitskii I. Ya. Na dosuge. Sbornik yuridicheskikh statei i issledovanii s 1870 g. T. 2 [At leisure. A Collection of Juridical Articles and investigations since 1870. Vol. 2.]. Saint Petersburg, M.M. Stasyulevich Publ., 1900. 608 p.

11. Foinitskii I. Ya. Crimonal and legal doctrine of complicity. Yuridicheskii vestnik= Juridical Bulletin, 1891, vol. VII. B. 1, no 1, pp. 3-28. (In Russian).

12. Foinitskii I. Ya. Uchenie o nakazanii $v$ svyazi $s$ tyur'movedeniem [Doctrine of punishment in the context of prison studies]. Moscow, Gorodets, Dobrosvet-2000 Publ., 2000. $464 \mathrm{p}$.

13. Esipov V. V. Ocherk russkogo ugolovnogo prava: Prestuplenie i prestupniki. Nakazanie $i$ nakazuemye. Chast' obshchaya [An essay of Russian criminal law: Crime and criminals. Punishment and punishable. General Part]. 2 ${ }^{\text {nd }}$ ed. Saint Petersburg, N.V. Vasil'ev Publ., 1898. $402 \mathrm{p}$.

14. Dril' D. A. Uchenie o prestupnosti i o merakh bor'by s neyu [Doctrine of criminality and on measures of struggle against it]. Saint Petersburg, Shipovnik Publ., 1912. 702 p.

15. Gogel' S. K. Kurs ugolovnoi politiki $v$ svyazi s ugolovnoi sotsiologiei [A course of criminal policy in the context of criminal sociology]. Saint Petersburg, Pravo Publ., 1910. $516 \mathrm{p}$.

16. Kistyakovskii A. F. Elementarnyi uchebnik obshchego ugolovnogo prava s podrobnym izlozheniem nachal russkogo ugolovnogo zakonodatel'stva. Chast' obshchaya [Elementary Textbook of General Criminal Law Basics with Detailed Presentation of Russian Criminal Legislation. General Part]. $2^{\text {nd }}$ ed. Kiev, I. i A. Davidenko Publ., 1882. 972 p.

17. Chubinskii M. P. Kurs ugolovnoi politiki [A Course of Criminal Policy]. Yaroslavl', Gubernskoe pravlenie Publ., 1909. 450 p.

\section{Baikal Research Journal}


18. Mokrinskii S. P. Nakazanie, ego tseli i predpolozheniya : v 3 ch. Ch. 1. Obshchee $i$ spetsial'noe preduprezhdenie prestuplenii [Punishment, its goals and supposition: in 3 parts. Part 1 General and Special prevention of crimes]. Moscow, Universitet Publ., 1902. $157 \mathrm{p}$.

19. Mokrinskii S. P. Nakazanie, ego tseli i predpolozheniya : v $3 \mathrm{ch}$. Ch. 3. Kazual'nyi $i$ potentsial'nyi momenty deistviya [Punishment, its goals and prevention: in 3 parts. Part 3. Casual and potential moments of action]. Tomsk, P. I. Makushin Publ., 1905. 263 p.

20. Poznyshev S. V. Uchenie o karatel'nykh merakh i mere nakazaniya. Kurs, sostavlennyi po lektsiyam [Doctrine of punitive measures and measure of punishment. A Course Made on Lectures]. Moscow, Obshchestvo vzaimopomoshchi studentov-yuristov Moskovskogo universiteta Publ., 1908. 185 p.

21. Poznyshev S. V. Osnovnye nachala nauki ugolovnogo prava: Obshchaya chast' ugolovnogo prava [Basic Principles of Criminal Law Science: General Part of Criminal Law]. $2^{\text {nd }}$ ed. Moscow, A.A. Kartsev Publ., 1912. 668 p.

22. Vladimirov L. E. Kurs ugolovnogo prava: $v 2$ ch. Ch. 1. Osnovy nyneshnego ugolovnogo prava [A Course of Criminal Law: in two parts. Basics of Current Criminal Law]. Moscow, I. D. Sytin Publ., 1908. 400 p.

\section{Информация об авторе}

Путинцев Андрей Владимирович - Аспирант, кафедра теории и истории государства и права, ФГАОУ ВО «Казанский (Приволжский) федеральный университет», 420008, Казань, ул. Кремлевская, 18, e-mail: chiefdom@уandex.ru.

\section{Author}

Andrey V. Putintsev - PhD Student, Chair of The Theory and History of State and Law, Kazan Federal University, 18, Kremlyovskaya str., Kazan, 420008; e-mail: chiefdom@yandex.ru.

\section{Для цитирования}

Путинцев А.В. Проблема объекта отношения уголовно-правовой ответственности в русской юридической мысли второй половины XIX - начала XX века / А.В. Путинцев // Baikal Research Journal. - 2017. — T. 8, № 3. — DOI : 10.17150/2411-6262.2017.8(3).24.

\section{For Citation}

Putintsev A.V. Object of relations of criminal and legal liability as a problem in Russian legal thought in mid $19^{\text {th }}$ - early $20^{\text {th }}$ century. Baikal Research Journal, 2017, vol. 8, no. 3. DOI: 10.17150/2411-6262.2017.8(3).24. (In Russian).

\section{Baikal Research Journal}

